Palavras chave:

Cafeeiro

Madeira alternativa

Valor agregado

Resíduo

Histórico:

Recebido | |/12/2009

Aceito 04/10/2013

Keywords:

Coffee plant

Wood alternative

Value-added

Waste

Correspondência: jreinaldo@dcf.ufla.br
Marisa Aparecida Pereira', Jose Reinaldo Moreira da Silva², Giovanni Francisco Rabelo², Anna Carolina de Almeida Andrade ${ }^{2}$

\section{PROPRIEDADES ANATÔMICAS, QUÍMICAS E DE DENSIDADE DA MADEIRA DE Coffea arabica L.}

RESUMO: O estado de Minas Gerais é o maior produtor de café do Brasil e a quantidade de resíduo nas lavouras pode ser adequada para subsidiar a confecção de produtos sólidos da madeira de Coffea arabica L., que atualmente é utilizada para fins energéticos ou permanece na área. Essa atividade agrega baixo valor ao material, além de promover a liberação de $\mathrm{CO}_{2}$ que possui efeito nocivo ao ambiente. $\mathrm{O}$ presente trabalho foi realizado com o objetivo de caracterizar tecnologicamente a madeira de Coffea arabica L. para potencializar sua utilização na confecção de móveis. Realizou-se a caracterização anatômica, química e de densidade básica da madeira de Coffea arabica L. A madeira apresentou densidade básica média de $0,608 \mathrm{~g} \cdot \mathrm{cm}^{-3}$. Na análise anatômica, a madeira apresentou camadas de crescimento distintas, vasos semiporosos com placas de perfuração simples, O parênquima axial é apotraqueal difuso em agregado, raios heterogêneos, não estratificados e fibras libriformes não septadas com pontuações areoladas distintas. Para a análise química os teores de extrativos em água fria e quente foram respectivamente de $6,1 \%$ e $9,6 \%$. O teor de cinzas encontrado foi de $0,68 \%$. Os dados foram comparados com a madeira de mogno (Swietenia macrophylla) e Piptadenia peregrina Benth, (angicovermelho) utilizadas na produção de móveis.

\section{ANATOMICAL AND CHEMICAL PROPERTIES AND DENSITY OF Coffea arabica L. WOOD}

ABSTRACT: The state of Minas Gerais is the largest producer of coffee in Brazil and the amount of residue in crops seems adequate to support production of solid wood products of Coffea arabica L., which is currently used for energy purposes or remains in the area. This activity adds insignificant value the coffee products and release $\mathrm{CO}_{2}$, which has harmful effects to the environment. This study was conducted with the aim of characterizing technologically Coffea arabica L. wood to enhance its use in furniture, to characterize its anatomical, chemical and wood basic density. The density showed an average of $0.608 \mathrm{~g} \cdot \mathrm{cm}^{-3}$. The anatomical analysis showed distinct growth layers, semiporosos vessels with simple perforation plates. The axial parenchyma is apotracheal and diffuse in the aggregate with heterogeneous rays, not laminated and fiber libriformes not septate with bordered pits distinct. The chemical content of extract in hot and cold water were respectively $6.1 \%$ and $9.6 \%$. The ash content was found to be $0.68 \%$. Data were comparable to those of mahogany (Swietenia macrophylla) and Piptadenia peregrina Benth, (angico-vermelho) used for the production of furniture. 


\section{INTRODUÇÃO}

A indústria moveleira necessita demonstrar sua preocupação com o meio ambiente e reduzir seus custos pela racionalização de uso dos insumos e matérias primas. Nos últimos anos, empregou madeiras oriundas de florestas nativas sem qualquer tipo de manejo.

O estado de Minas Gerais é o maior produtor de café do Brasil e a quantidade de madeira proveniente de suas lavouras podem subsidiar algumas linhas de produção das micros e pequenas empresas de móveis locais, utilizada conjuntamente a outras madeiras e materiais.

O setor moveleiro é grande gerador de empregos e de renda para o Brasil, sendo formado, principalmente, por micro e pequenas empresas de capital nacional (FARIAS; LANGER; SILVA, 2008). Assim, surge a necessidade de se investir em madeiras alternativas para o seu suprimento, fato que alivia a pressão existente sobre as espécies nativas.

A utilização da madeira do cafeeiro na confecção de novas linhas de móveis é uma alternativa para os resíduos da indústria cafeeira. Os resíduos são, na maioria das vezes, simplesmente abandonados e queimados nas próprias lavouras ou, são usados como fonte de energia. Sua queima ocasiona maior concentração de $\mathrm{CO}_{2}$ na atmosfera.

As exigências do mercado moveleiro não se restringem à caracterização física e mecânica da matéria-prima, mas também existe a preocupação com o contexto ambiental.

O presente trabalho foi realizado com o objetivo de caracterizar as propriedades anatômicas, químicas e de densidade básica da madeira de Coffea arabica L., para potencializar sua utilização na confecção de móveis.

\section{MATERIAL E MÉTODOS}

Foi utilizada a madeira de Coffea arabica L., proveniente do município de Três Pontas/MG. O local em que foi coletado o material possui, aproximadamente, cinco hectares de área plantada com a cultivar "mundo novo", espécie Coffea arabica L., dispostos no sistema adensado, com aproximadamente 15 anos de idade.

O arbusto inteiro do cafeeiro foi retirado com $\circ$ auxilio de um trator. Foram selecionados aproximadamente $15 \mathrm{~m}^{3}$ de madeira, com dimensões de 100 a $130 \mathrm{~cm}$ de comprimento e 8 a $10 \mathrm{~cm}$ de diâmetro, mensurado na metade de seu comprimento.

Todo o material foi conduzido ao Laboratório de Usinagem da Madeira (DCF/ UFLA), armazenado em pilhas, sem contato direto com o chão, em uma área aberta e coberta, para a secagem natural, durante o período de cinco meses. Para a realização das análises, foram retirados 12 discos da base e topo de diferentes arbustos.

$\mathrm{Na}$ análise anatômica, foram adotadas as normas da International Association of Wood Anatomists - IAWA (1989). Para tanto, foram retirados 12 discos da base de diferentes arbustos. Foram feitas aproximadamente 120 leitura por lâminas para cada descrição anatômica. As mensurações e as descrições das estruturas anatômicas dos vasos/poros, parênquima axial, raios e fibras, foram executadas por meio do equipamento com câmera de captura de imagem com software WinCellPro (Regent Instruments), no Laboratório de Anatomia (DCF/UFLA). Segundo a NBR II94I (ASSOCIAÇÃO BRASILEIRA DE NORMAS TÉCNICAS - ABNT, 2003), determinou-se a densidade básica da madeira, pelo método de imersão, utilizando os 12 discos da base.

A análise química foi realizada em 12 troncos, escolhidos aleatoriamente, dos arbustos. Segundo a Associação Brasileira Técnica de Celulose e Papel - ABTCP (1974), Goldschimid (197I) e Gomide e Demuner (1986) foram retirados cavacos que foram transformados em serragem e classificados, produzindo uma amostra única, que foi utilizada em triplicata nas análises químicas.

\section{RESULTADOS E DISCUSSÃO}

A madeira apresentou camadas de crescimento distintas, individualizadas por zonas fibrosas mais escuras (Figura la), em decorrência da região apresentar estação seca anual com a duração de 5 meses. Worbes (1995) afirmou que estação seca com duração de 2 a 3 meses no ano é condição ambiental necessária para espécies de regiões tropicais formarem camadas de crescimento em seu lenho.

Vasos/poros: semiporosos, arranjo radial, agrupamentos predominantemente solitários (90\%), com contorno circular, de 22-44-67 $\mu \mathrm{m}$ de diâmetro, numerosíssimos (em média 50 poros $\cdot \mathrm{mm}^{-2}$ ); elementos vasculares de 32-60-88 $\mu \mathrm{m}$ de comprimento, apêndices variando de curtos a longos e presentes em ambas as extremidades; placas de perfuração simples, pontoações intervasculares alternas muito pequenas, medindo, em média $2 \mu \mathrm{m}$ de diâmetro, pontoações guarnecidas presentes; pontoações raio-vasculares com aréolas distintas semelhantes às intervasculares em tamanho e forma (Figura la e Id). 

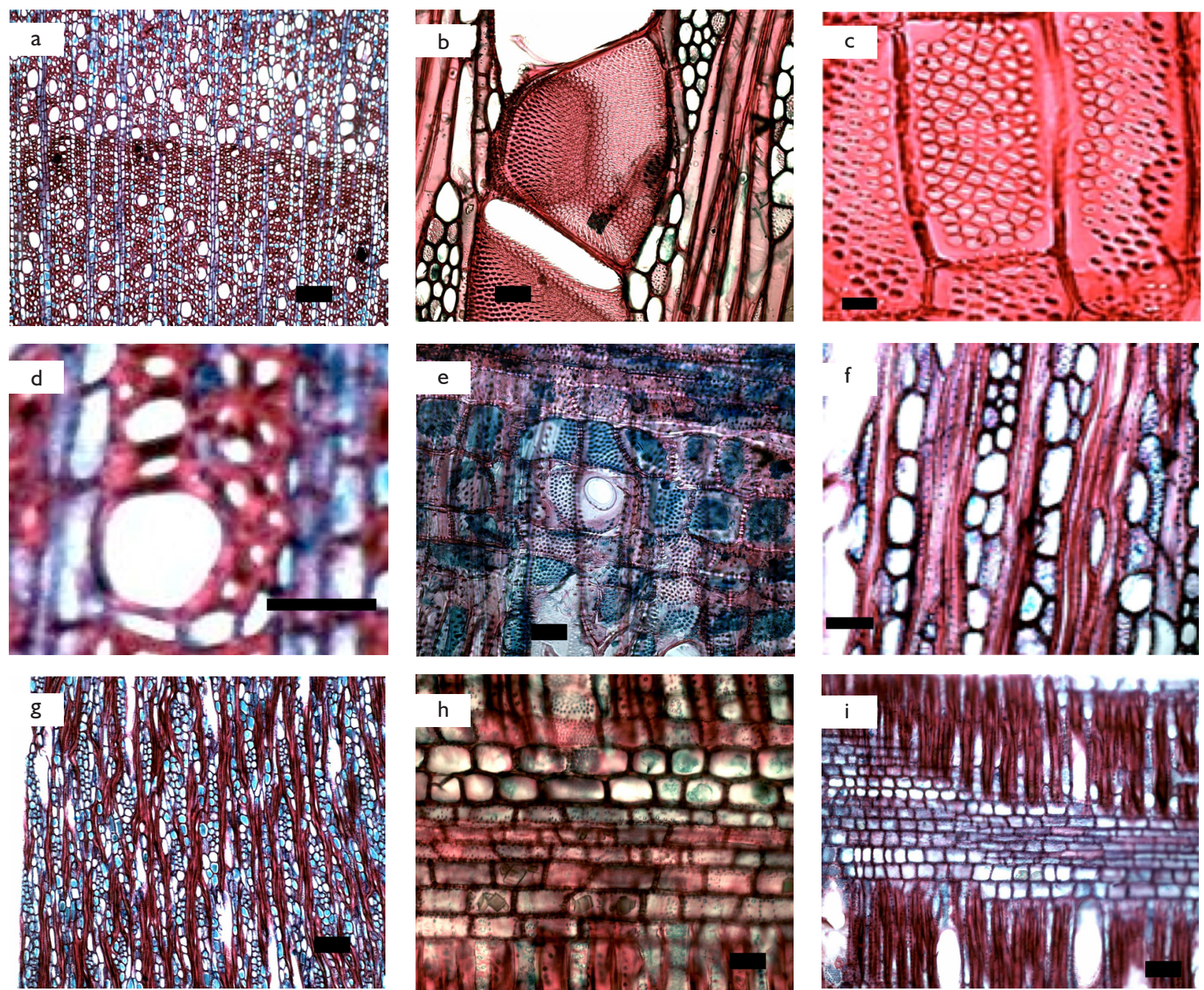

FIGURA I Caracterização anatômica da madeira de Coffea arabica L., em que: a = camada de crescimento; b = placa de perfuração simples; $c=$ pontoações; $d=$ contorno circular dos poros, $e=$ camada de crescimento, $f=$ células perfuradas de parênquima radial; $g$ = raios: heterogêneos, não estratificados, $h=$ presença de cristais prismáticos de oxalato de cálcio e $\mathrm{i}=$ células do raio eretas, procumbentes e quadradas.

FIGURE I Anatomical characterization of the wood of Coffe $a$ arabica L., in which: $a=$ the layer growth; $b=$ plate simple; $c=$ pits; $\mathrm{d}=$ pore circular outline, and layer growth; $\mathrm{f}=$ perforated cells parenchyma; $\mathrm{g}=$ ray heterogeneous, not elastic; $\mathrm{h}=$ presence of prismatic crystals of calcium oxalate and $\mathrm{i}=$ ray cells upright, procumbent and square.

Segundo Carlquist (1988), anéis semiporosos, como encontrados na madeira do cafeeiro, proporcionam à espécie vantagem sobre a porosidade difusa, pois reúnem segurança e eficiência na condução de água. Essa característica é importante durante o processo de secagem, fase indispensável para a produção de madeira sólida.. Placa de perfuração (simples), parênquima axial (apotraqueal) e os raios (heterogêneo) e fibras (espessura da parede fina) estão coerentes com as outras espécies da família rubiácea (PAULA; ALVES, 1970).

Alguns estudos indicam que a presença de placas de perfuração simples nos vasos pode se relacionar à maior eficiência na condução de água dentro da planta (CARLQUIST, I988; WHEELER; BAAS, I99I). Os estudos Schulte e Castle (1993) não sustentam essa teoria porque o ganho em condutividade hidráulica é muito pequeno em vasos com placas de perfuração simples, quando comparados com os de placas de perfuração múltiplas que, semelhante à porosidade, afetam a secagem da madeira.

Parênquima axial: apotraqueal difuso em agregado, de I-2 fileiras de células (Figura 4d).

Raios: heterogêneos, não estratificados, formado por células procumbentes com 2 a 4 filas de células marginais quadradas e ou eretas, unisseriados e multisseriados (2-3), altos, altura de 7-24-50 células e 
440-1080-1960 $\mu \mathrm{m}$ de comprimento, largura de 2-3-5 células e 5I-2I-93 $\mu \mathrm{m}$ de largura, frequência de 4-83 raios $/ \mathrm{mm}$; presença de células envolventes, raios com dois tamanhos distintos, células radiais perfuradas (Figura le, Ig e Ii).

Fibras: libriformes não septadas com pontoações areoladas distintas (Figura le), curtas a longas, 900I.363-I.835 $\mu \mathrm{m}$ de comprimento, paredes de delgadas a espessa, diâmetro do lume 6-II-I7 $\mu \mathrm{m}$, espessura da parede $4-7-12 \mu \mathrm{m}$.

Presença de cristais prismáticos de oxalato de cálcio, em câmaras localizadas nas células eretas e ou nas quadradas dos raios (Figura Ih). A ausência de tilos pode estar relacionada ao tamanho reduzido dos elementos de vaso, inferiores a $80 \mu \mathrm{m}$ e das pontoações intervasculares, menores que $4 \mathrm{~mm}^{2}$. Dimensões nessa ordem de grandeza não propiciam o desenvolvimento dos tilos (BONSEN; KUCERA, 1990).

Comparando com madeiras utilizadas no setor moveleiro como o mogno (Swietenia macrophylla) algumas características, como placa de perfuração simples e pontoações intervasculares alternas diminutas estão presentes na madeira de Coffea arabica L. Essas características interferem na permeabilidade da madeira, que afeta na sua secagem e o processo de adesão (colagem).

A densidade básica média encontrada para a espécie foi de $0,608 \mathrm{~g} \cdot \mathrm{cm}^{-3}$, o que a classifica como de densidade média, de acordo com os dados do Instituto de Pesquisas Tecnológicas - IPT (1956). Observou-se baixa variação dos valores da densidade básica entre base e o topo das peças (Tabela I).

TABELA I Variação da densidade básica da madeira de Coffea arabica L. no sentido da base para o topo.

TABLE I Variation of wood basic density of Coffea arabica L. from the base to top

\begin{tabular}{lccc}
\hline \multirow{2}{*}{$\begin{array}{c}\text { Densidade } \\
\left(\mathrm{g} \cdot \mathrm{cm}^{-3}\right)\end{array}$} & \multicolumn{3}{c}{ Posição na peça } \\
\cline { 2 - 4 } & Base & Topo & Média geral \\
\hline Mínimo & 0,584 & 0,577 & - \\
Média & 0,614 & 0,603 & 0,608 \\
Máximo & 0,647 & 0,652 & - \\
\hline $\begin{array}{l}\text { Coeficiente de } \\
\text { variação }(\%)\end{array}$ & 2,9 & 3,2 & 3,2 \\
\hline
\end{tabular}

Verifica-se uma queda da densidade básica com o aumento da altura do tronco, um dos padrões gerais para as folhosas (PANSHIN; ZEEUW, 1980). As médias da densidade básica da base e do topo foram de 0,6I4 e $0,603 \mathrm{~g} \cdot \mathrm{cm}^{-3}$, respectivamente.
O teor de extrativo em água fria encontrado para a madeira de Coffea arabica L. foi de 6,1\%. A madeira de Piptadenia peregrina Benth, (angico-vermelho) apresentou teor de extrativo em água fria de 4,9 e 5,4\%, para o cerne e o alburno, respectivamente (MARCATI, 1992). Para os teores de extrativos em água quente, encontrouse $9,6 \%$ para a madeira de Coffea arabica L. Já, o angicovermelho apresentou 6,8 e 7,1\% no cerne e no alburno, respectivamente (MARCATI, 1992). Os valores do angico vermelho estão abaixo dos encontrados para madeira do Coffea arabica L. O teor de cinzas para a madeira de Coffea arabica L. foi de $0,68 \%$.

\section{CONCLUSÕES}

A madeira do cafeeiro foi considerada de média densidade e apresentou pequena variação ao longo do seu fuste. Não observou diferenças marcantes nas características anatômicas da madeira do cafeiro. Não observou valores discrepantes das características da madeira do cafeeiro, comparativamente às madeiras de angico vermelho e mogno, podendo ser indicada para fabricação de móveis. Contudo, sugere-se realizar a caracterização mecânica e a análise da qualidade do processamento mecânico desse material.

\section{REFERÊNCIAS}

ASSOCIAÇÃO BRASILEIRA DE NORMAS TÉCNICAS. NBR I I94 I: determinação da densidade básica da madeira. Rio de Janeiro, 2003. 6 p.

ASSOCIAÇÃO BRASILEIRA TÉCNICA DE CELULOSE E PAPEL. Normas técnicas ABCP. São Paulo, 1974. 6 p.

BONSEN, K. J. M.; KUCERA, L. J. Vessel occlusions in plants: morphological, functional and evolutionary aspects. IAWA Bulletin, Leiden, v. II, n. 4, p. 393-399, 1990.

CARLQUIST, S. Comparative wood anatomy: systematic ecological and evolutionary aspects of dicotyledonean wood. Berlin: Springer-Verlag, 1988. 15 p.

FARIAS, M.G.; LANGER, R.R.; SILVA, A. Ecodesign e produção mais limpa: inovação em produto no APL madeira móveis. Florianópolis: UFSC, 2008. 13 p.

GOLDSCHIMID, O. Ultraviolet spectra. In: SARKANEN, K. V.; LUDWIG, C. H. (Ed.). Lignins: occurrence, formation, structure and reactions. New York: J. Wiley, 197I. p. 24I298.

GOMIDE, J. L.; DEMUNER, B. J. Determinação do teor de lignina em material lenhoso: método Klason modificado. O Papel, São Paulo, v. 47, n. 8, p. 36-38, 1986. 
INSTITUTO DE PESQUISAS TECNOLÓGICAS. Métodos de ensaios adotados no IPT para o estudo de madeiras nacionais: tabelas de resultados obtidos para madeiras nacionais, nomenclatura das madeiras nacionais. 2. ed. São Paulo, 1956. 62 p. (Boletim Técnico, 31).

INTERNATIONALASSOCIATIONOFWOODANATOMISTS. List of microscopic features for hardwood identification. IAWA Bulletin, Leiden, v. I0, p. 220-332, 1989.

MARCATI, C. R. Caracterização tecnológica da madeira Angico-Vermelho (Benth). 1992. 147 f. Dissertação (Mestrado em Ciências Florestais) - Universidade Federal de Viçosa, Viçosa, 1992.

PANSHIN, A. J.; ZEEUW, C. de. Textbook of wood technology. $4^{\text {th }}$ ed. New York: McGraw-Hill Book, 1980. 722 p.
PAULA, J. E.; ALVES, J. L. de H. Madeiras nativas: anatomia, dendrologia, dendrometria, produção e uso. Brasília: Fundação Mokiti Okada-MOA, 1997. 543 p.

SCHULTE, P. J.; CASTLE, A. Water flow through vessel perforation plates: the effects of plate angle and thickness for liriodendron tulipifera. Las Vegas: University of Nevada Las Vegas, 1993. $15 \mathrm{p}$.

WHEELER, E. A.; BAAS, P. A survey of the fossil record for dicotyledonous wood and its significance for evolutionary and ecological wood anatomy. IAWA Bulletin, Leiden, v. 12, n. 5, p. 275-332, May 199I.

WORBES, M. How to measure growth dynamics in tropical trees: a review. IAWA Bulletin, Leiden, v. I6, n. 4, p. 337$35 \mathrm{I}$, Apr. 1995. 
